\title{
Tamoxifen reduces fat mass by boosting reactive oxygen species
}

\author{
L Liu', P Zou ${ }^{1}$, L Zheng ${ }^{1}$, LE Linarelli ${ }^{1}$, S Amarell ${ }^{1}$, A Passaro ${ }^{1}$, D Liu ${ }^{1}$ and Z Cheng ${ }^{\star, 1}$
}

As the pandemic of obesity is growing, a variety of animal models have been generated to study the mechanisms underlying the increased adiposity and development of metabolic disorders. Tamoxifen (Tam) is widely used to activate Cre recombinase that spatiotemporally controls target gene expression and regulates adiposity in laboratory animals. However, a critical question remains as to whether Tam itself affects adiposity and possibly confounds the functional study of target genes in adipose tissue. Here we administered Tam to Cre-absent forkhead box 01 (Fox01) floxed mice (f-Fox01) and insulin receptor substrate Irs1//rs2 double floxed mice (df-Irs) and found that Tam induced approximately $30 \%$ reduction $(P<0.05)$ in fat mass with insignificant change in body weight. Mechanistically, Tam promoted reactive oxygen species (ROS) production, apoptosis and autophagy, which was associated with downregulation of adipogenic regulator peroxisome proliferator-activated receptor gamma and dedifferentiation of mature adipocytes. However, normalization of ROS potently suppressed Tam-induced apoptosis, autophagy and adipocyte dedifferentiation, suggesting that ROS may account, at least in part, for the changes. Importantly, Tam-induced ROS production and fat mass reduction lasted for 4-5 weeks in the f-Fox01 and df-Irs mice. Our data suggest that Tam reduces fat mass via boosting ROS, thus making a recovery period crucial for posttreatment study.

Cell Death and Disease (2015) 6, e1586; doi:10.1038/cddis.2014.553; published online 8 January 2015

Excess fat mass or adiposity is the hallmark of obesity, the rapidly growing epidemic. ${ }^{1,2}$ In the United States, over twothirds of adults are overweight or obese according to the statistics of years 2011-2012. ${ }^{3}$ For children, the overweight or obese population accounts for about $25 \%$ in the $2-5$-year olds and $33 \%$ in school students (including adolescents). ${ }^{3}$ It is estimated that obesity care accounts for $21 \%$ of national healthcare expenditures, that is, 190.2 billion US dollars per year, in the United States. ${ }^{4}$ Because adipose tissue is an important endocrine organ, which secretes adipokines or cytokines that regulate inflammatory responses and metabolic homeostasis, aberrant adiposity dysregulates adipokine levels and leads to a variety of metabolic disorders and complications, such as diabetes and cardiovascular diseases. ${ }^{5}$ As such, the healthcare burden that obesity imposes on the society is far greater.

To understand the molecular mechanism of obesity development, various rodent models have been generated to study the gain or loss of functions of different genes. ${ }^{6,7}$ To this end, the Cre/lox site-specific recombination system has been versatile to generate conditional mouse mutants, controlling gene expression and activity in target tissues. ${ }^{8,9}$ In particular, Tamoxifen (Tam) is used to activate Cre recombinases spatiotemporally in vivo through intraperitoneal (I.P.) or subcutaneous administration. ${ }^{10-12}$ Injection of Tam at a dose of $1-8 \mathrm{mg} / \mathrm{kg}$ body weight for 5 consecutive days deletes target genes, thus establishing a versatile system to study functional genes in obesity. ${ }^{8-12}$

The use of Tam in clinical treatments has led to the argument about its potential effect on body fat or weight gain in human patients. ${ }^{13,14}$ It raises the question as to whether and how Tam influences adipocytes and fat mass in the experimental animal models after administration. Exclusion of direct regulation of adiposity by Tam as a confounding factor in animal models is critical to better understand target genes in adipogenesis and metabolic homeostasis. In the present work, we present the evidence that 5-day administration of Tam significantly reduces mouse fat mass, which persists till weeks 4-5 after the treatment. At the cellular level, Tam promotes the production of reactive oxygen species (ROS), which is accompanied with enhanced apoptosis, autophagy and adipocyte dedifferentiation. However, treatment of adipocytes with antioxidant $\mathrm{N}$-acetyl cysteine (NAC) dramatically counteracted Tam-induced ROS and suppressed apoptotic and autophagic markers, concomitant with reversal of adipocyte dedifferentiation. In vivo, fat mass was restored upon the normalization of ROS, which is associated with suppressed adipocyte dedifferentiation and downregulated apoptotic and autophagic markers. Our data reveal a ROSmediated mechanism by which Tam induces fat mass reduction. As it may confound the posttreatment study, deliberate determination of the recovery period after Tam

\footnotetext{
${ }^{1}$ Department of Human Nutrition, Foods and Exercise, Fralin Life Science Institute, College of Agriculture and Life Science, Virginia Tech, Blacksburg, VA, USA ${ }^{*}$ Corresponding author: Z Cheng, Department of Human Nutrition, Foods and Exercise, Fralin Life Science Institute, College of Agriculture and Life Science, Virginia Tech, 1981 Kraft Drive, Blacksburg, VA 24061, USA. Tel: +1 (540) 231 9445; Fax: +1 (540) 231 5522; E-mail: zcheng@ @t.edu.

Abbreviations: Carboxy-DCFDA, 5,6-carboxy-2',7'-dichlorofluorescein diacetate; Cas3(c), cleaved caspase 3; df-Irs, Irs1/Irs2 double floxed mice; eWAT, epididymal white adipose tissue; FoxO1, forkhead box 01; f-FoxO1, FoxO1 floxed mice; HO1, heme oxygenase 1; Irs, insulin receptor substrate; I.P., intra-peritoneal; LC3, microtubuleassociated protein 1A/1B-light chain 3-phosphatidylethanolamine conjugate; NAC, N-acetyl cysteine; PPAR $\gamma$, peroxisome proliferator-activated receptor gamma; ROS, reactive oxygen species; Tam, Tamoxifen

Received 02.9.14; revised 10.11.14; accepted 17.11.14; Edited by A Finazzi-Agrò
} 
administration is essential to understand the functions of target genes using Tam-induced knockout mice.

\section{Results}

Tam induced fat mass reduction in mice. To test the effect of Tam on fat mass, we conducted a 5-day I.P. administration of Tam (1 $\mathrm{mg} / 20 \mathrm{~g}$ body weight) on forkhead box $\mathrm{O} 1$ (FoxO1) floxed mice bearing no Cre recombinase (f-FoxO1), ${ }^{15-17}$ by following a standard protocol established previously. ${ }^{12}$ Two weeks after Tam administration, the body fat was reduced by $34 \%(P<0.05)$ in $\mathrm{f}-\mathrm{FoxO} 1$ mice (Figure 1a). To validate the findings, we treated insulin receptor substrate 1 (Irs1) and Irs2 double floxed mice without Cre recombinase (df-Irs) in a similar way, ${ }^{15,16}$ and found that fat mass was also significantly reduced (26\%, $P<0.05$; Supplementary Figure $\mathrm{S} 1 \mathrm{~A})$. However, the changes in body weight were insignificant between vehicle (sunflower oil) control and the treatment groups (Figure 1b; Supplementary Figure S1B). Monitoring of the kinetics of fat mass change suggested that the reduction was persistent till week 5 (week 4 in df-Irs mice), after which the fat percentage was comparable to the pretreatments (Figure 1a; Supplementary Figure S1A). In line with this finding, the weight of epididymal white adipose tissue (eWAT) was significantly reduced in Tam-treated f-FoxO1 mice at week 2, while there was no significant difference at week 6
(Figures 1c and d). By contrast, injection of the vehicle caused indiscernible change in the body fat mass (Figure 1a; Supplementary Figure S1A). Therefore, the reduction of fat mass in mice arose primarily from Tam treatment. Given that both mouse models shared this phenotype, we used f-FoxO1 mice for the following mechanistic study.

Tam promoted apoptosis and autophagy in adipose tissue. The regulators of apoptosis and autophagy were implicated in the regulation of fat mass. ${ }^{18-23}$ To examine whether Tam had effects on apoptosis and autophagy, we used eWAT at weeks 2 and 6 after Tam administration and analyzed the mediators of apoptosis and autophagy - the activated or cleaved caspase 3 (Cas3 (c)) and microtubule-associated protein $1 \mathrm{~A} / 1 \mathrm{~B}$-light chain 3-phosphatidylethanolamine conjugate (LC3), respectively. ${ }^{24,25}$ As shown in Figures $2 a$ and $b$, Tam treatment increased the level of Cas3(c) by 6.8 -fold $(P<0.0001)$ and the autophagosomal marker LC3-II by 1.9 -fold $(P<0.05)$ at week 2 . However, these changes were largely reversed at week 6 and showed no statistical significance (Figures $2 c$ and d).

Tam promoted the production of ROS. ROS and the resultant oxidative stress have an important role in apoptosis and autophagy. ${ }^{26-28}$ To examine whether ROS and oxidative stress was involved in Tam-induced effects, we analyzed heme oxygenase 1 ( $\mathrm{HO} 1)$, the sensitive indicator of cellular

a

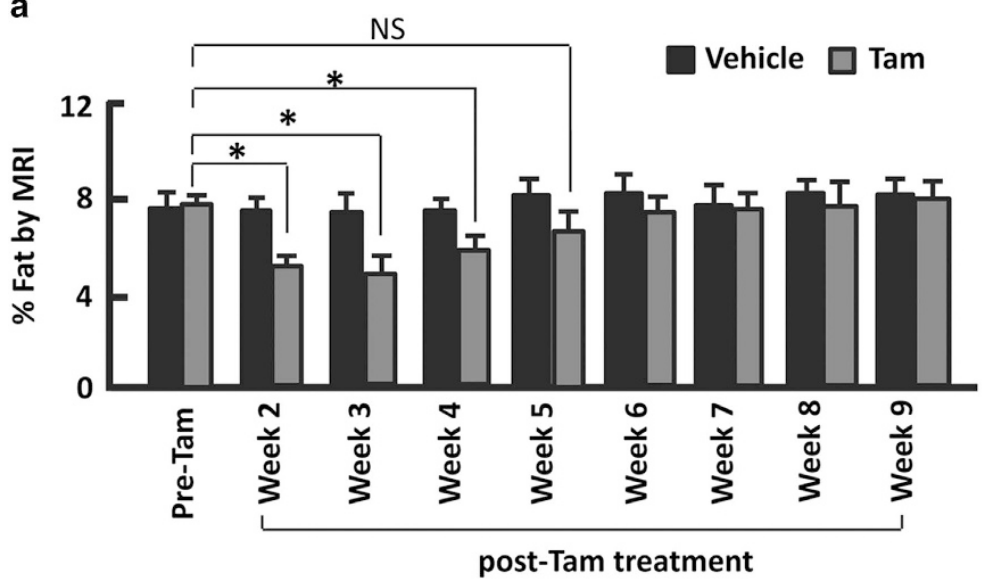

b

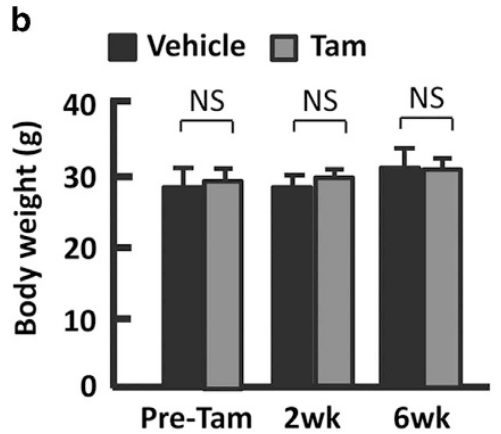

C

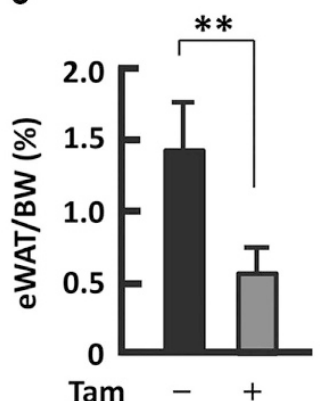

d

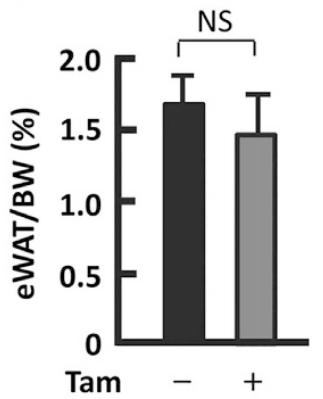

Figure 1 Tam reduced fat mass in f-FoxO1 mice. (a) The kinectics of fat mass regulation after 5-day administration of Tam. (b) Measurement of body weight before Tam treatment (pre-Tam), 2 weeks (2wk) and 6 weeks (6wk) after Tam injection. (c) The weight of epididymal adipose tissue (eWAT) at week 2 in mice treated with Tam. (d) The weight of eWAT at week 6 in mice treated with Tam. $n=4-6 ;{ }^{*} P<0.05$; ${ }^{\star *} P<0.01$; NS, not significant 
oxidative stress. ${ }^{29}$ Tam treatment upregulated $\mathrm{HO} 1$ protein levels in adipose tissue by over 7 -fold $(P<0.0001)$ in mice at week 2; however, at week 6 , the $\mathrm{HO} 1$ abundance in the treated mice was comparable to that in untreated mice, showing no statistical significance (Figures $3 a$ and b). Interestingly, the $\mathrm{HO} 1$ levels in untreated mice were higher at week 6 than at week 2, supporting the notion that $\mathrm{HO} 1$ expression increases with age. ${ }^{30,31}$ Measurement of ROS
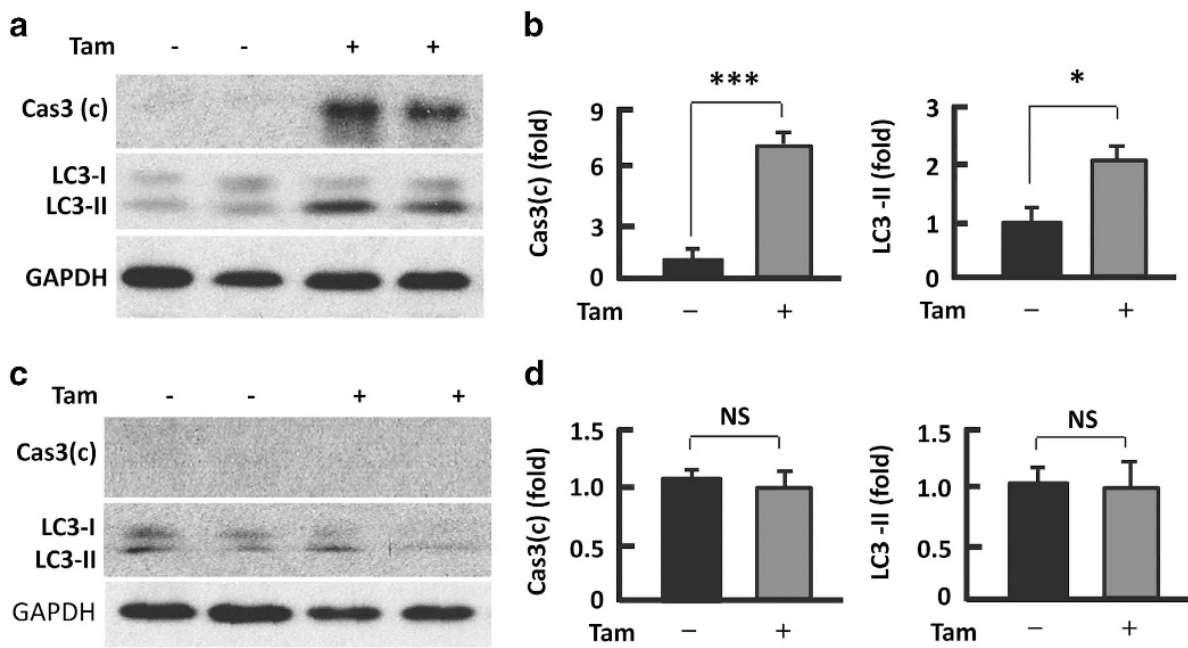

d
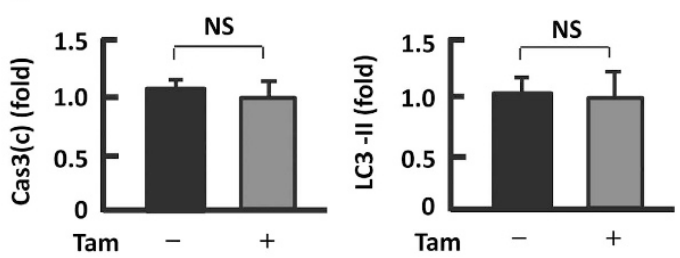

Figure 2 Tam increased apoptotic and autophagic regulators in adipose tissue. (a and b) At week 2 after Tam administration, western blotting (a) was performed to analyze Cas3(c) and LC3 with densitometric analysis (b) of western blotting images using the NIH ImageJ software; $n=5-7$. (c and d) At week 6 after Tam administration, western blotting (c) was performed to analyze Cas3 (c) and LC3, and densitometric analysis (d) of western blotting images with the NIH ImageJ software; $n=5-7$. GAPDH (glyceraldehyde 3-phosphate dehydrogenase) was probed as a loading control. ${ }^{\star} P<0.05$; ${ }^{* \star \star} P<0.0001$; NS, not significant

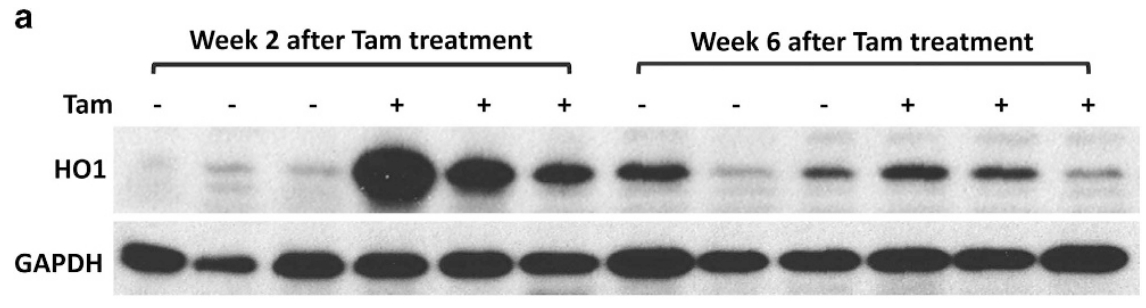

b

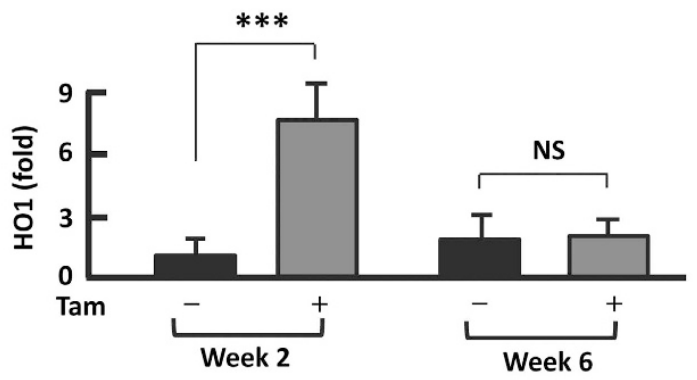

C
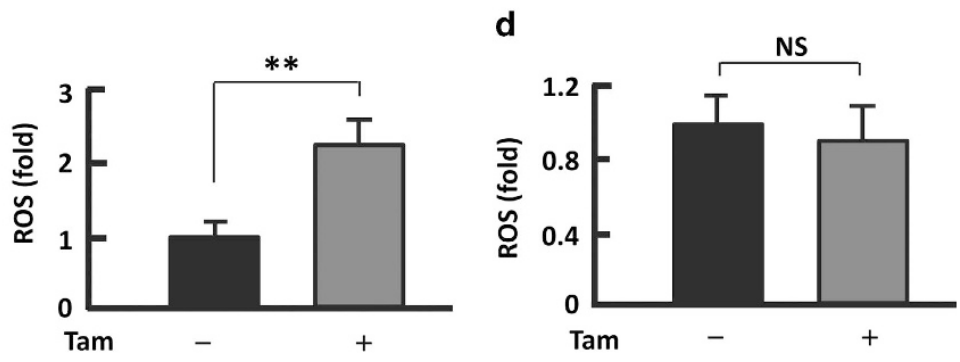

Figure 3 Tam promoted ROS and oxidative stress. (a) Western blotting analysis of $\mathrm{HO} 1$ in mouse adipose tissues at weeks 2 and 6, respectively, after Tam administration, with GAPDH (glyceraldehyde 3-phosphate dehydrogenase) probed as a loading control. (b) Densitometric analysis of western blotting images using the NIH ImageJ software; $n=6-8$. (c) Measurement of ROS in adipose tissue at week 2 after Tam administration $(n=3-4)$. (d) Measurement of ROS in adipose tissue at week 6 after Tam administration $(n=3-4) .{ }^{* \star} P<0.01 ;{ }^{* \star \star} P<0.0001 ; \mathrm{NS}$, not significant 
levels in adipose tissue indicated a 2.3-fold elevation in Tam-treated mice than in vehicle-treated mice at week 2 (Figure 3c), but they became statistically insignificant at week 6 (Figure 3d). Of note, the upregulation and downregulation of ROS and HO1 levels seems to coincide well with the changes in Cas3(c), LC3-II and fat mass (Figures 1-3).

Antioxidant abolished Tam-induced ROS, apoptosis and autophagy. To map the interaction between ROS and other Tam-induced cellular events, we treated 3T3L1 adipocytes with Tam combined with a potent ROS-scavenger NAC. ${ }^{32,33}$ As observed in adipose tissue, Tam induced significant upregulation of $\mathrm{HO} 1$ in 3T3L1 adipocytes, and the effect was dose dependent in the tested range of $0-128 \mu \mathrm{M}$ (Supplementary Figure S2). Tam also promoted ROS production by 2.5 -fold $(P<0.01)$ in 3T3L1 adipocytes (Figure 4a) and significantly upregulated the apoptosis regulators Cas3(c) and autophagosomal marker LC3-II (Figures $4 \mathrm{~b}$ and $\mathrm{c}$ ). However, inclusion of NAC in the treatments suppressed Tan-induced elevation of ROS and $\mathrm{HO} 1$ and normalized the protein levels of Cas3(c) and LC3-II (Figures $4 a-c)$.

Antioxidant reversed Tam-induced reduction in cell density and adipocyte population. Because alteration in adipocyte number affects adiposity, ${ }^{2}$ we asked whether Tam treatment influenced cell density. Compared with the vehicletreated adipocytes, Tam-treated cells showed a significant decrease in cell density $(24 \%, P<0.05)$, consistent with the upregulation of apoptotic marker (Figures 5a, b and d, Figures $4 \mathrm{~b}$ and $\mathrm{c}$ ). Interestingly, the population of lipiddroplet-containing cells (i.e., mature adipocytes) also declined (36\%, $P<0.05)$, implying a process of 'dedifferentiation' might be induced by Tam (Figures $5 a, b$ and e). ${ }^{34-36}$ Regardless, addition of the ROS-scavenger NAC largely restored the cell density and population of mature adipocytes (Figures 5c and e).

Antioxidant reversed Tam-induced downregulation of peroxisome proliferator-activated receptor gamma (PPARy). PPARy is a key regulator of adipogenesis (de novo generation of mature adipocytes) and adipocyte dedifferentiation. ${ }^{34,35,37}$ The observation of reduced population of mature adipocytes after Tam treatment prompted us to analyze the effect of Tam on PPARy. As shown in Figure 6a, PPAR $y$ protein levels were reduced by $74 \%(P<0.01)$ in Tamtreated adipocytes. However, co-treatment of the adipocytes with Tam and NAC significantly restored PPARy level. These data suggest that Tam may regulate adipogenesis or population of mature adipocytes through ROS-mediated downregulation of PPAR $y$. Consistent with this hypothesis, we found that the PPAR $y$ levels were dramatically decreased $(69 \%, P<0.01)$ in the adipose tissues of Tam-treated mice at week 2 (Figure $6 b$ ), which is accompanied by elevation of ROS and HO1 (Figures $3 a-c)$. At week 6 when ROS and HO1 levels returned to normal (Figures $3 a, b$ and d); however, the abundance of PPARy also returned to the values comparable to those in the control mice (Figure 6c). In addition, the reversal of ROS overproduction and PPARY
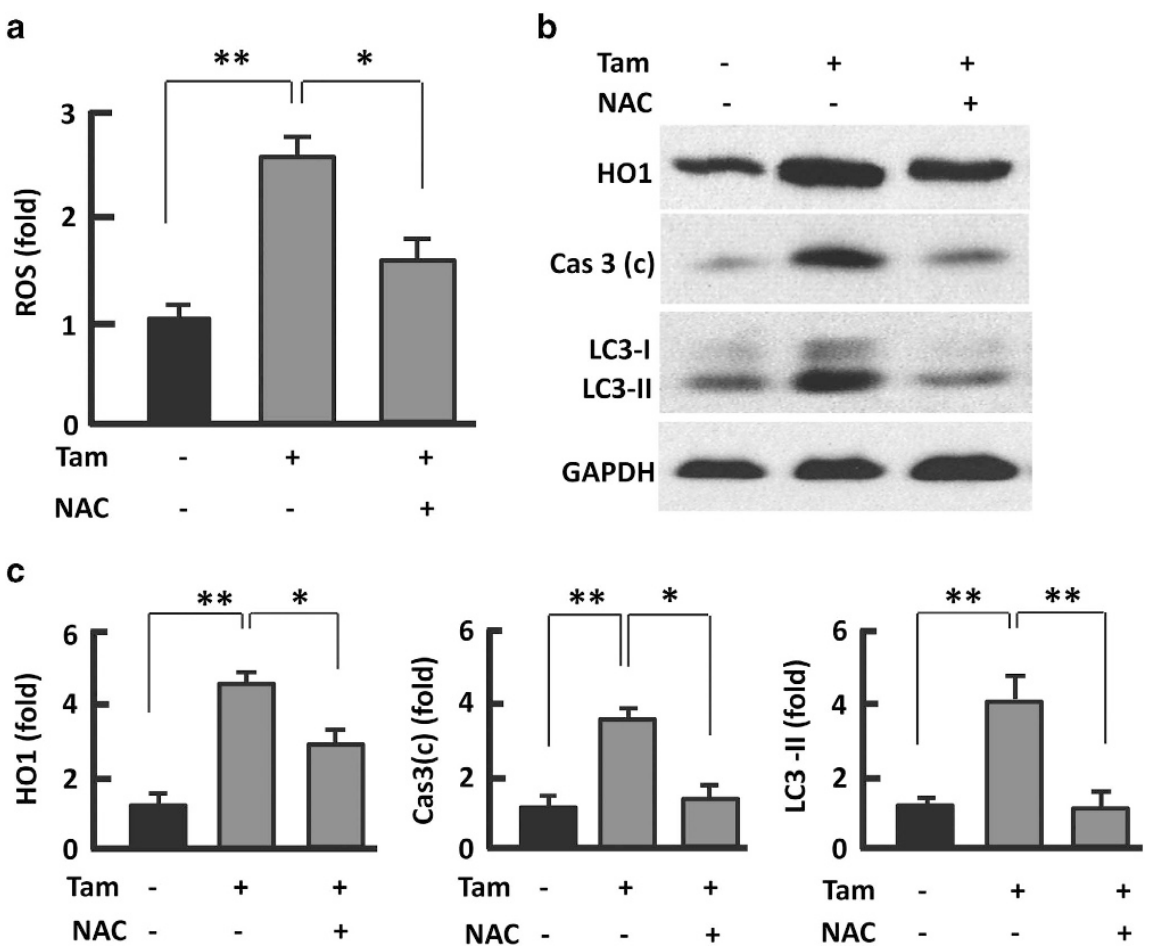

Figure 4 Antioxidant NAC attenuated ROS level and reversed Tam effects. (a) Measurement of ROS in 3T3L1 adipocytes. (b and c) Western blotting analysis (b) of HO, Cas3 (c) and LC3 in 3T3L1 adipocytes after 48-h treatment with Tam (128 $\mu \mathrm{M})$ or Tam $(128 \mu \mathrm{M})$ plus NAC $(1 \mathrm{mM})$, with densitometric analysis (c) of western blotting images using the NIH ImageJ software; GAPDH (glyceraldehyde 3-phosphate dehydrogenase) was probed as a loading control. $n=3-5 ;{ }^{*} P<0.05 ;{ }^{* \star} P<0.01$ 


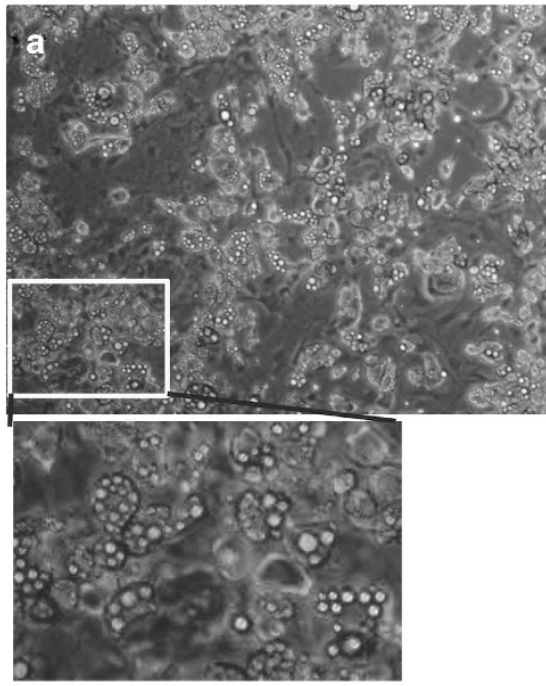

d

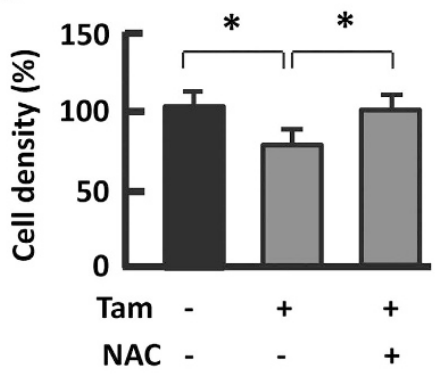

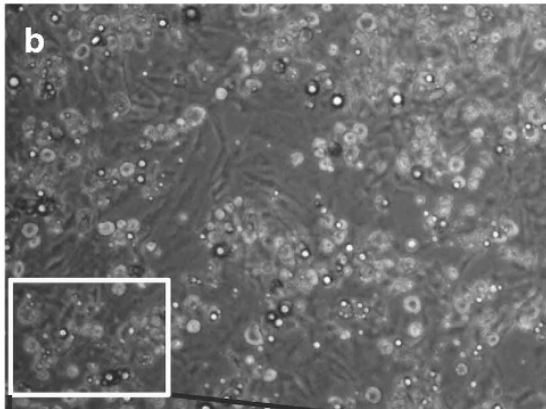
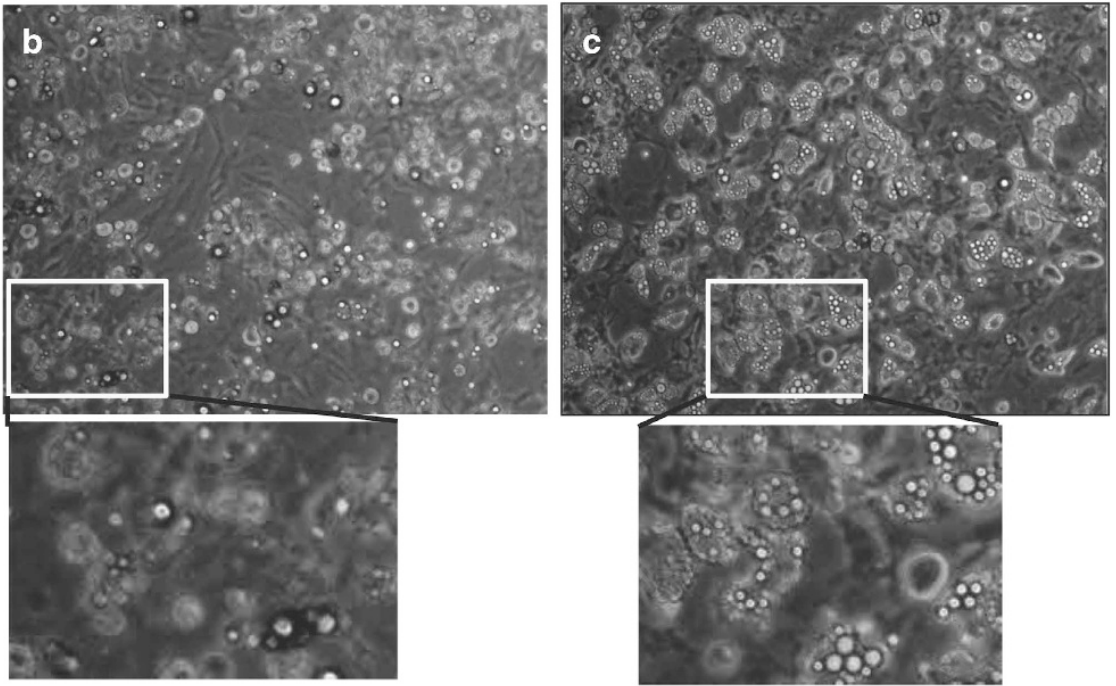

e

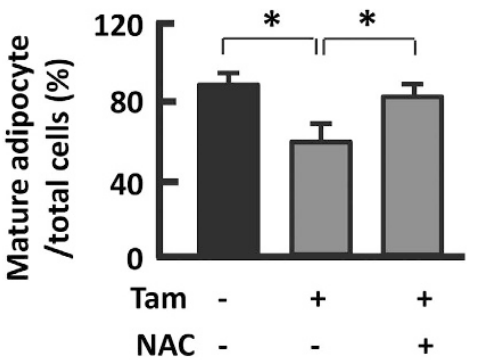

Figure 5 Antioxidant NAC mitigates Tam effect on cell density and mature adipocyte population. (a-c) Microscopy imaging of $3 T 3 L 1$ adipocytes treated with vehicle (a), $128 \mu \mathrm{M}$ Tam $(\mathbf{b})$ and Tam $(128 \mu \mathrm{M})$ plus NAC $(1 \mathrm{mM})(\mathbf{c})$. The microscope was set at $\times 100$. (d and e) Measurement of cell density and population of mature adipocytes using the NIH ImageJ software; $n=6-8 .{ }^{*} P<0.05$

suppression was accompanied by normalization of fat mass at week 6 (Figures 1, 3 and 6 Supplementary Figure S1).

\section{Discussion}

Tam has been widely used to activate inducible Cre recombinase and knockout target genes in mechanistic studies of adipose development and metabolic homeostasis. ${ }^{8,11,12,38-41}$ However, the effect of Tam administration on adipocytes and adipose tissue has not been investigated to the best of our knowledge. In this study, we chose to use f-FoxO1 bearing no Cre recombinase for Tam treatment, aiming to rule out the effect of Cre activation (or gene deletion) on fat mass. We found that a 5-day administration of Tam led to a significant reduction of fat mass in mice, which lasted for 4-5 weeks after the last injection. The findings were validated in Cre-absent df-Irs mice. The Tam-induced fat mass reduction could confound the effects of gene knockout, making it critical to allow for 6 weeks as a recovery period before further study is conducted. Note that the recovery period may vary with different animal models, thus warranting a deliberate determination for a specific laboratory model to establish a reliable experimental system.

The mechanism by which Tam reduces fat mass includes several cellular events. Tam treatment increased apoptosis and autophagy, the processes that reduce adipocyte number and have been implicated in adipose regulation. ${ }^{2,18-23}$ Indeed, the cell density and population of mature adipocytes decreased after Tam treatment. Tam also promoted adipocyte dedifferentiation and ROS production, whereas normalization of ROS level markedly mitigated Tam-induced adipocyte dedifferentiation, apoptosis and autophagy, concomitant with restoration of mature adipocyte population and fat mass. Together, our data strongly suggest that the short-term (5-day) treatment with Tam reduces fat mass via boosting ROS production.

Tam was shown to induce ROS and oxidative stress in breast cancer cells, hepatoblastoma cells, retinal cells and platelets through activation of $\mathrm{NAD}(\mathrm{P}) \mathrm{H}$ oxidase, the enzyme that also promotes ROS production in macrophages. ${ }^{32,42-46}$ The ROS-boosting effect of Tam was extended and further validated by our study in adipocytes and adipose tissues. Importantly, we found that ROS elevation resulted in PPARY downregulation and adipocyte dedifferentiation, which support the notion that mature adipocytes undergo dedifferentiation under stress conditions. ${ }^{34,35}$ It was shown that proinflammatory adipocytokines (e.g., TNFa) could promote adipocyte dedifferentiation through downregulation of PPARy. ${ }^{34,35}$ Given that ROS elevation or oxidative stress increases TNFa production, ${ }^{47}$ Tam may promote adipocyte dedifferentiation 
a
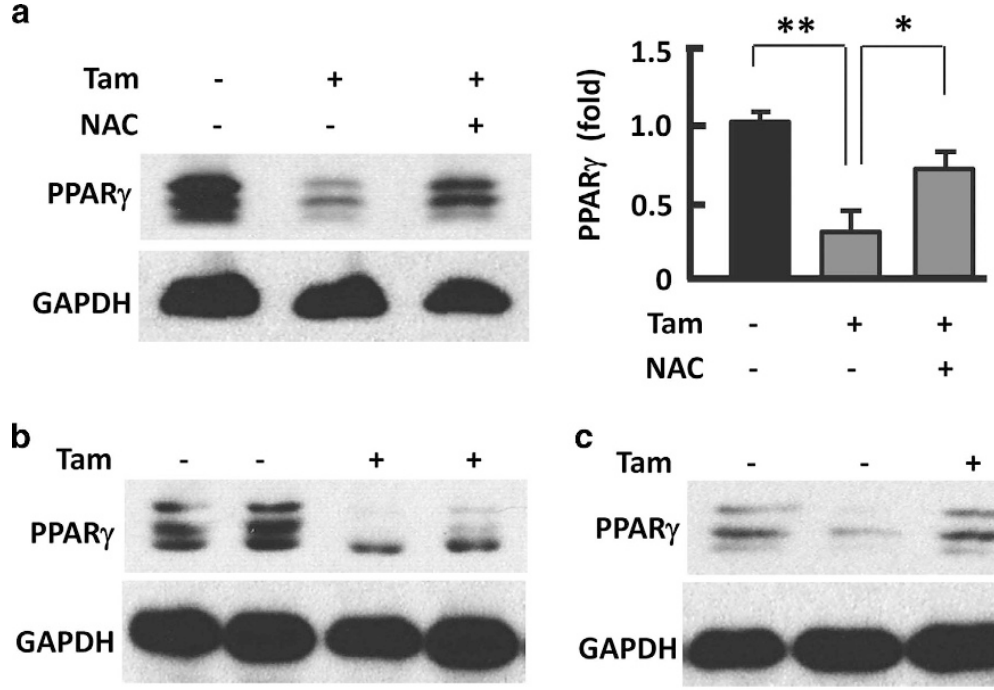

C
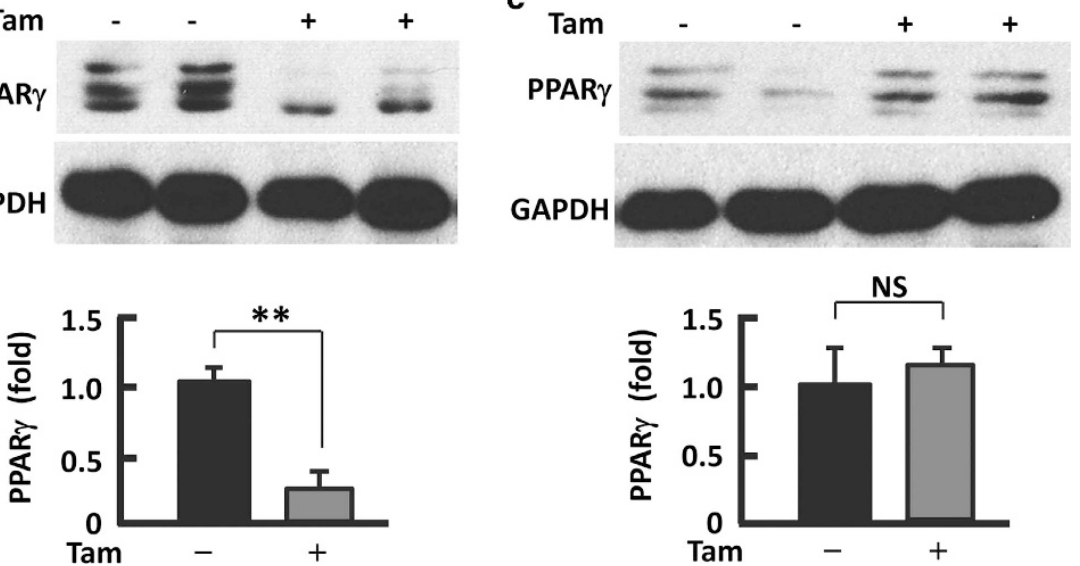

Figure 6 Counteracting or normalizing ROS reduced Tam effect on PPAR $\gamma$. (a) Western blotting analysis (left panel) of PPAR $\gamma$ in 3T3L1 adipocytes after 48-h treatment with $\operatorname{Tam}(128 \mu \mathrm{M})$ or Tam $(128 \mu \mathrm{M})$ plus NAC $(1 \mathrm{mM})$, with densitometric analysis (right panel) of western blotting images using the NIH Image J software; $n=3-5$. (b) At week 2 after Tam administration, western blotting (upper panel) was performed to analyze PPAR $\gamma$, with densitometric analysis (lower panel) of western blotting images using the NIH ImageJ software; $n=3-5$. (c) At week 6 after Tam administration, western blotting (upper panel) was performed to analyze PPAR $\gamma$, with densitometric analysis (lower panel) of western blotting images using the NIH ImageJ software; $n=3-5$. GAPDH (glyceraldehyde 3-phosphate dehydrogenase) was probed as a loading control. ${ }^{*} P<0.05 ;{ }^{* \star} P<0.01$

by activating a ROS-TNFa-PPAR $y$ axis. To this end, macrophage infiltration in adipose tissue might have a role, because these phagocytes were shown to instigate ROS and TNFa production and also respond sensitively to ROS- and TNFamediated signaling cascades. ${ }^{46,48}$

The effect of Tam on fat mass in humans, for example, breast cancer patients, remains inconclusive. Although Tam was reported to increase fat mass through its anti-estrogenic effect, ${ }^{13}$ recent studies loosened the conclusion by showing that Tam has no effect on the fat mass in breast cancer patients. ${ }^{14}$ It should be noted that the Tam dosage and treatment duration for mice in this study significantly differs from that for the long-term Tam treatment of breast cancer patients. To activate Cre recombinase to knock out target genes, animal models are typically treated for 5 consecutive days (administration of $1-8 \mathrm{mg} / 20 \mathrm{~g}$ body weight or 50 $400 \mathrm{mg} / \mathrm{kg}$ body weight, once a day). ${ }^{8-12}$ However, Tam therapy for breast cancer patients in the United States generally lasts 5 years, with a dose of $20 \mathrm{mg}$ (either one $20 \mathrm{mg}$ tablet or two $10 \mathrm{mg}$ tablets) taken by month once a day. ${ }^{49-51}$ Assuming that the body weight of breast cancer patients ranges from $50 \mathrm{~kg}$ to $80 \mathrm{~kg}$, the average daily use of Tam would be $0.25-0.4 \mathrm{mg} / \mathrm{kg}$, a dosage being $0.06-0.8 \%$ of that used in animal models. Owing to different dosage and treatment duration, the effect of Tam on mouse fat mass observed in this study might not be phenocopied in breast cancer patients with Tam therapy.

\section{Materials and Methods}

Materials. Dulbecco's modified Eagle's (DMEM) medium was from Corning Inc. (Manassas, VA, USA). Fetal bovine serum (FBS) was from GeneMate (Kaysville, UT, USA). Dexamethasone, 3-isobutyl-1-methylxanthine (IBMX), rosiglitazone and Tam were purchased from Cayman chemical (Ann Arbor, MI, USA). Penicillin/ streptomycin (P/S) was from GE Healthcare Life Sciences HyClone Laboratories (Logan, UT, USA). Insulin and NAC were from Sigma-Aldrich (St. Louis, MO, USA). Phosphate-buffered saline (PBS) was from Caisson Laboratories, Inc. (North Logan, UT, USA).

Mice. The Fox01 floxed mice (f-Fox01) and Irs1//rs2 double floxed mice (df-Irs) were bred and housed as previously described. ${ }^{15,16,52}$ Briefly, the mice were housed in plastic cages on a 12-h light-dark photocycle, with free access to water and regular chow diet. Before Tam treatment experiments, male mice (14-16-week old) were weighed, and fat mass was measured with a Bruker Minispec LF90 NMR Analyzer (Bruker Optics, Billerica, MA, USA). Then the mice were transferred to a biosafety level 2 (BSL2) room and administered with Tam (1 mg/20 $\mathrm{g}$ body weight) or the vehicle (sunflower oil) by I.P. injection (once a day for 5 consecutive days). After Tam administration, the cages were changed every 2 days until week 2 , when the mice were transferred into BSL1 room, and the measurement of body fat mass was resumed. Depending on the experimental design, the mice were weighed and killed to harvest tissue for snap freezing in liquid nitrogen, at week 2 or week 6 after Tam treatment. All the procedures followed the $\mathrm{NIH}$ guideline and were approved by the Virginia Tech Institutional Animal Care and Use Committee.

Cell culture and treatment. 3T3L1 preadipocytes (ATCC CL-173, Manassas, VA, USA) were cultured in basal media (i.e., DMEM media supplemented with $10 \% \mathrm{FBS}, 100 \mathrm{units} / \mathrm{ml}$ penicillin and $100 \mu \mathrm{g} / \mathrm{ml}$ streptomycin $(1 \times \mathrm{P} / \mathrm{S}))$, at $37^{\circ} \mathrm{C}$ in a humidified atmosphere of $5 \% \mathrm{CO}_{2}$. The media were replaced every 2 days. Differentiation of 3T3L1 cells was induced as described previously with minor modifications. ${ }^{53}$ Briefly, 3T3L1 cells were grown to confluence (day 0) and maintained in fresh basal media (BMI) for 2 days (days 1-2). At the end of day 2 , 
BMI medium was changed to differentiation medium I (DMI): DMEM supplemented with $10 \% \mathrm{FBS}, \mathrm{P} / \mathrm{S}(1 \times)$, IBMX $(0.5 \mathrm{mM})$, dexamethasone $(1 \mu \mathrm{M})$, insulin $(1 \mu \mathrm{g} / \mathrm{ml})$, and rosiglitazone $(2 \mu \mathrm{M})$. At the end of day 4 , DMI medium was changed to differentiation medium II (DMII): DMEM supplemented with $10 \% \mathrm{FBS}, \mathrm{P} / \mathrm{S}(1 \times)$, and insulin $(1 \mu \mathrm{g} / \mathrm{ml})$. At the end of day 6 , DMII medium was changed to basal media (BMII), and the cells were maintained in BMII (replaced with fresh basal medium every 2 days) until fully differentiated (day 12). As a control, preadipocytes were maintained in BMI till day 12 and supplied with fresh medium every other day. Upon full differentiation, 3T3L1 adipocytes were treated with Tam for $48 \mathrm{~h}$ at the concentrations of $0,8,16,32,64$ and $128 \mu \mathrm{M}$ and the vehicle $0.1 \%$ sunflower as a treatment control. ${ }^{12}$ When applicable, NAC was added at a concentration of $1 \mathrm{mM}$ with Tam for a 48-h treatment to study the role of ROS ${ }^{32}$ Images of the cells were captured on day 12 with a Nikon ECLIPSE TS100 microscope (Melville, NY, USA), and the cell counting and population analysis was conducted with the NIH ImageJ software (Bethesda, MD, USA).

ROS measurement. ROS in adipocytes and adipose tissue was measured as previously described, ${ }^{54,55}$ with a cell-permeable dye 5,6-carboxy-2',7'-dichlorofluorescein diacetate (Carboxy-DCFDA, Molecular Probes, Grand Island, NY, USA). Snap-frozen adipose tissues were weighed and transferred into buffered medium ( $5 \mathrm{mmol} / / \mathrm{HEPES}$ in PBS) for quick thawing to improve the probe diffusion. After rapid thawing, the medium was discarded. Samples were exposed to $8 \mu \mathrm{M}$ Carboxy-DCFDA in fresh medium and were incubated at $37^{\circ} \mathrm{C}$ for 45 min under agitation. Medium was then removed, and samples were further incubated in a lysis buffer $(0.1 \%$ SDS, Tris- $\mathrm{HCl}, \mathrm{pH} 7.4)$ for $15 \mathrm{~min}$ at $4{ }^{\circ} \mathrm{C}$. After homogenization, samples were centrifuged at $16000 \times \mathrm{g}$ for $20 \mathrm{~min}$ at $4^{\circ} \mathrm{C}$. Supernatants were collected and subjected to fluorescence analysis at $530 \mathrm{~nm}$ under excitation at $485 \mathrm{~nm}$ using a Synergy H4 Hybrid Multi-Mode Microplate Reader (BioTek Instruments, Winooski, VT, USA).

To measure ROS in 3T3L1 adipocytes, $1-5 \times 10^{6}$ cells were harvested with typsin and washed three times with cold PBS, followed by incubation with $8 \mu \mathrm{M}$ CarboxyDCFDA in fresh medium $\left(5 \mathrm{mmol} / / \mathrm{HEPES}\right.$ in PBS) and were incubated at $37^{\circ} \mathrm{C}$ for $45 \mathrm{~min}$ under agitation. Medium was then removed, and samples were further incubated in PLC lysis buffer: ${ }^{15,52}$ (30 mM Hepes, pH 7.5, $150 \mathrm{mM} \mathrm{NaCl}, 10 \%$ glycerol, $1 \%$ Triton X-100, $1.5 \mathrm{mM} \mathrm{MgCl}$, 1 mM EGTA, $10 \mathrm{mM} \mathrm{NaPPi}, 100 \mathrm{mM} \mathrm{NaF}$, $1 \mathrm{mM} \mathrm{Na}_{3} \mathrm{VO}_{4}$ ) supplemented with protease inhibitor cocktail (Roche, Branchburg, $\mathrm{NJ}$, USA) and $1 \mathrm{mM} \mathrm{PMSF}$ for $15 \mathrm{~min}$ at $4^{\circ} \mathrm{C}$. After homogenization, samples were centrifuged at $16000 \times \mathrm{g}$ for $20 \mathrm{~min}$ at $4^{\circ} \mathrm{C}$. Supernatants were collected and subjected to fluorescence analysis at $530 \mathrm{~nm}$ under excitation at $485 \mathrm{~nm}$, and the total protein was determined with DC protein assay (Bio-Rad, Hercules, CA, USA) on a Synergy H4 Hybrid Multi-Mode Microplate Reader (BioTek Instruments, Inc.). The ROS levels were normalized to the total protein for each cell dish.

Western blotting. To prepare tissue lysates, snap-frozen adipose tissues were weighed and homogenized with a Bullet Blender (Next Advance, Averill Park, NY, USA) in PLC lysis buffer supplemented with protease inhibitor cocktail (Roche), $1 \mathrm{mM}$ PMSF, $10 \mu \mathrm{M}$ TSA (Trichostatin A, Selleckchem, Houston, TX, USA) and $5 \mathrm{mM}$ Nicotinamide (Alfa Aesar, Ward Hill, MA, USA). ${ }^{15,52}$ For cell lysates, the 3T3L1 adipocytes were washed with ice-cold PBS and homogenized with a Bullet Blender. Total protein concentrations of the lysates were determined using the DC protein assay (Bio-Rad). Western blotting and image analysis were conducted as described previously. ${ }^{15}$ Antibody catalog numbers and vendors are as follows: cleaved caspase-3 Rabbit mAb (9664) and LC3B antibody (no. 2775) from Cell Signaling Technology (Beverly, MA, USA); PPAR-gamma antibody (MA5-14889) and GAPDH antibody (MA5-15738) from Pierce (Rockford, IL, USA) or Thermo Fisher Scientific (Waltham, MA, USA); and HO1 antibody (3391-100) from Biovision (Milpitas, CA, USA).

Statistical analyses. All results are expressed as means \pm S.D. and are analyzed by analysis of variance to determine $P$ values; $P<0.05$ was considered statistically significant.

\section{Conflict of Interest}

The authors declare no conflict of interest.

Acknowledgements. We thank Dr. Ronald Depinho (University of Texas MD Anderson Cancer Center) and Dr. Morris F White (Children's Hospital Boston,
Harvard Medical School) for providing the f-FoxO1 and df-Irs mice, respectively. Funding for this work was provided, in part, by the Virginia Agricultural Experiment Station and the Hatch Program of the National Institute of Food and Agriculture, US Department of Agriculture (to ZC), and by grant 1R01AT007077 from the National Center for Complementary and Alternative Medicine in the National Institutes of Health (to DL). Publication of this article was supported by Virginia Tech's Open Access Subvention Fund.

1. Cheng Z, Almeida FA. Mitochondrial alteration in type 2 diabetes and obesity: an epigenetic link. Cell Cycle 2014; 13: 890-897.

2. Wang QA, Tao C, Gupta RK, Scherer PE. Tracking adipogenesis during white adipose tissue development, expansion and regeneration. Nat Med 2013; 19: 1338-1344.

3. Ogden CL, Carroll MD, Kit BK, Flegal KM. Prevalence of childhood and adult obesity in the United States, 2011-2012. JAMA 2014; 311: 806-814.

4. Cawley J, Meyerhoefer $\mathrm{C}$. The medical care costs of obesity: an instrumental variables approach. J Health Econ 2012; 31: 219-230.

5. Niswender K. Diabetes and obesity: therapeutic targeting and risk reduction - a complex interplay. Diabetes Obes Metab 2010; 12: 267-287.

6. Kanasaki K, Koya D. Biology of obesity: lessons from animal models of obesity. J Biomed Biotechnol 2011; 2011: 197636.

7. Nilsson C, Raun K, Yan FF, Larsen MO, Tang-Christensen M. Laboratory animals as surrogate models of human obesity. Acta Pharmacol Sin 2012; 33: 173-181.

8. Feil S, Valtcheva N, Feil R. Inducible Cre mice. Methods Mol Biol 2009; 530: 343-363.

9. Li M, Indra AK, Warot X, Brocard J, Messaddeq N, Kato $S$ et al. Skin abnormalities generated by temporally controlled RXRalpha mutations in mouse epidermis. Nature 2000; 407: 633-636.

10. Reinert RB, Kantz J, Misfeldt AA, Poffenberger G, Gannon M, Brissova M et al. Tamoxifen-induced Cre-loxP recombination is prolonged in pancreatic islets of adult mice. PLoS One 2012; 7: e33529.

11. Sassmann A, Offermanns S, Wettschureck N. Tamoxifen-inducible Cre-mediated recombination in adipocytes. Genesis 2010; 48: 618-625.

12. Imai T, Jiang M, Chambon $P$, Metzger $D$. Impaired adipogenesis and lipolysis in the mouse upon selective ablation of the retinoid $\mathrm{X}$ receptor alpha mediated by a tamoxifen-inducible chimeric Cre recombinase (Cre-ERT2) in adipocytes. Proc Natl Acad Sci USA 2001; 98: 224-228.

13. Nguyen MC, Stewart RB, Banerij MA, Gordon DH, Kral JG. Relationships between tamoxifen use, liver fat and body fat distribution in women with breast cancer. Int J Obes Relat Metab Disord 2001; 25: 296-298.

14. Francini G, Petrioli R, Montagnani A, Cadirni A, Campagna S, Francini E et al. Exemestane after tamoxifen as adjuvant hormonal therapy in postmenopausal women with breast cancer: effects on body composition and lipids. Br J Cancer 2006; 95: 153-158.

15. Cheng Z, Guo S, Copps K, Dong X, Kollipara R, Rodgers JT et al. Foxo1 integrates insulin signaling with mitochondrial function in the liver. Nat Med 2009; 15: 1307-1311.

16. Dong XC, Copps KD, Guo S, Li Y, Kollipara R, DePinho RA et al. Inactivation of hepatic Foxo1 by insulin signaling is required for adaptive nutrient homeostasis and endocrine growth regulation. Cell Metab 2008; 8: 65-76.

17. Paik JH, Kollipara R, Chu G, Ji H, Xiao Y, Ding $Z$ et al. FoxOs are lineage-restricted redundant tumor suppressors and regulate endothelial cell homeostasis. Cell 2007; 128: 309-323.

18. Yeh WC, Bierer BE, McKnight SL. Rapamycin inhibits clonal expansion and adipogenic differentiation of 3T3-L1 cells. Proc Natl Acad Sci USA 1995; 92: 11086-11090.

19. Bell A, Grunder L, Sorisky A. Rapamycin inhibits human adipocyte differentiation in primary culture. Obes Res 2000; 8: 249-254.

20. Polak P, Cybulski N, Feige JN, Auwerx J, Ruegg MA, Hall MN. Adipose-specific knockout of raptor results in lean mice with enhanced mitochondrial respiration. Cell Metab 2008; 8: $399-410$.

21. Pattingre S, Bauvy C, Levade T, Levine B, Codogno P. Ceramide-induced autophagy: to junk or to protect cells? Autophagy 2009; 5: 558-560.

22. Gullicksen PS, Hausman DB, Dean RG, Hartzell DL, Baile CA. Adipose tissue cellularity and apoptosis after intracerebroventricular injections of leptin and 21 days of recovery in rats. Int J Obes Relat Metab Disord 2003; 27: 302-312.

23. Della-Fera MA, Qian H, Baile CA. Adipocyte apoptosis in the regulation of body fat mass by leptin. Diabetes Obes Metab 2001; 3: 299-310.

24. Tanida I, Ueno T, Kominami E. LC3 and Autophagy. Methods Mol Biol 2008; 445: 77-88.

25. Porter AG, Janicke RU. Emerging roles of caspase-3 in apoptosis. Cell Death Differ 1999; 6 : 99-104.

26. Yuan L, Wei S, Wang J, Liu X. Isoorientin induces apoptosis and autophagy simultaneously by reactive oxygen species (ROS)-related p53, PI3K/Akt, JNK, and p38 signaling pathways in HepG2 cancer cells. J Agric Food Chem 2014; 62: 5390-5400.

27. Liu SY, Chen CL, Yang TT, Huang WC, Hsieh CY, Shen WJ et al. Albumin prevents reactive oxygen species-induced mitochondrial damage, autophagy, and apoptosis during serum starvation. Apoptosis 2012; 17: 1156-1169.

28. Ghavami S, Eshragi M, Ande SR, Chazin WJ, Klonisch T, Halayko AJ et al. S100A8/A9 induces autophagy and apoptosis via ROS-mediated cross-talk between mitochondria and lysosomes that involves BNIP3. Cell Res 2010; 20: 314-331. 
29. Poss KD, Tonegawa S. Reduced stress defense in heme oxygenase 1-deficient cells. Proc Natl Acad Sci USA 1997; 94: 10925-10930.

30. Hirose W, Ikematsu K, Tsuda R. Age-associated increases in heme oxygenase-1 and ferritin immunoreactivity in the autopsied brain. Leg Med (Tokyo) 2003; 5: S360-S366.

31. Lavrovsky Y, Song CS, Chatterjee B, Roy AK. Age-dependent increase of heme oxygenase-1 gene expression in the liver mediated by NFkappaB. Mech Ageing Dev 2000; 114: 49-60.

32. Cho KS, Yoon YH, Choi JA, Lee SJ, Koh JY. Induction of autophagy and cell death by tamoxifen in cultured retinal pigment epithelial and photoreceptor cells. Invest Ophthalmol Vis Sci 2012; 53: 5344-5353.

33. Suzuki YJ, Tsuchiya M, Packer L. Thioctic acid and dihydrolipoic acid are novel antioxidants which interact with reactive oxygen species. Free Radic Res Commun 1991; 15: 255-263.

34. Zhang B, Berger J, Hu E, Szalkowski D, White-Carrington S, Spiegelman BM et al. Negative regulation of peroxisome proliferator-activated receptor-gamma gene expression contributes to the antiadipogenic effects of tumor necrosis factor-alpha. Mol Endocrinol 1996; 10: 1457-1466.

35. Xing H, Northrop JP, Grove JR, Kilpatrick KE, Su JL, Ringold GM. TNF alpha-mediated inhibition and reversal of adipocyte differentiation is accompanied by suppressed expression of PPARgamma without effects on Pref-1 expression. Endocrinology 1997; 138: 2776-2783.

36. De Pauw A, Tejerina S, Raes M, Keijer J, Arnould T. Mitochondrial (dys)function in adipocyte (de)differentiation and systemic metabolic alterations. Am J Pathol 2009; 175: 927-939.

37. Spiegelman BM. PPAR-gamma: adipogenic regulator and thiazolidinedione receptor. Diabetes 1998; 47: 507-514.

38. Terrand J, Bruban V, Zhou L, Gong W, El Asmar Z, May P et al. LRP1 controls intracellular cholesterol storage and fatty acid synthesis through modulation of Wnt signaling. J Biol Chem 2009; 284: 381-388

39. Imai T, Takakuwa R, Marchand S, Dentz E, Bornert JM, Messaddeq N et al. Peroxisome proliferator-activated receptor gamma is required in mature white and brown adipocytes for their survival in the mouse. Proc Natl Acad Sci USA 2004; 101: 4543-4547.

40. Dali-Youcef N, Mataki C, Coste A, Messaddeq N, Giroud S, Blanc S et al. Adipose tissuespecific inactivation of the retinoblastoma protein protects against diabesity because of increased energy expenditure. Proc Natl Acad Sci USA 2007; 104: 10703-10708.

41. Konishi M, Nakamura H, Miwa H, Chambon $\mathrm{P}$, Ornitz DM, Itoh N. Role of Fgf receptor $2 \mathrm{c}$ in adipocyte hypertrophy in mesenteric white adipose tissue. Mol Cell Endocrinol 2008; 287: 13-19.

42. Shah VP, Chegini HA, Vishneski SR, Weatherman RV, Blackmore PF, Dobrydneva Y. Tamoxifen promotes superoxide production in platelets by activation of PI3-kinase and NADPH oxidase pathways. Thromb Res 2012; 129: 36-42.

43. Kallio A, Zheng A, Dahllund J, Heiskanen KM, Harkonen P. Role of mitochondria in tamoxifen-induced rapid death of MCF-7 breast cancer cells. Apoptosis 2005; 10: 1395-1410.

44. Bursch W, Ellinger A, Kienzl H, Torok L, Pandey S, Sikorska M et al. Active cell death induced by the anti-estrogens tamoxifen and $\mathrm{ICl} 164384$ in human mammary carcinoma cells (MCF-7) in culture: the role of autophagy. Carcinogenesis 1996; 17: 1595-1607.
45. Lee YS, Kang YS, Lee SH, Kim JA. Role of $N A D(P) H$ oxidase in the tamoxifen-induced generation of reactive oxygen species and apoptosis in HepG2 human hepatoblastoma cells. Cell Death Differ 2000; 7: 925-932.

46. Forman HJ, Torres M. Reactive oxygen species and cell signaling: respiratory burst in macrophage signaling. Am J Respir Crit Care Med 2002; 166: S4-S8.

47. Esposito K, Nappo F, Marfella R, Giugliano G, Giugliano F, Ciotola M et al. Inflammatory cytokine concentrations are acutely increased by hyperglycemia in humans: role of oxidative stress. Circulation 2002; 106: 2067-2072.

48. Parameswaran N, Patial S. Tumor necrosis factor-alpha signaling in macrophages. Crit Rev Eukaryot Gene Expr 2010; 20: 87-103.

49. Fisher B, Costantino J, Redmond C, Poisson R, Bowman D, Couture $\mathrm{J}$ et al. A randomized clinical trial evaluating tamoxifen in the treatment of patients with node-negative breast cancer who have estrogen-receptor-positive tumors. N Engl J Med 1989; 320: 479-484.

50. Gail MH, Costantino JP, Bryant J, Croyle R, Freedman L, Helzlsouer $\mathrm{K}$ et al. Weighing the risks and benefits of tamoxifen treatment for preventing breast cancer. J Natl Cancer Inst 1999; 91: 1829-1846.

51. Reis SE, Costantino JP, Wickerham DL, Tan-Chiu E, Wang J, Kavanah M. Cardiovascular effects of tamoxifen in women with and without heart disease: breast cancer prevention trial. National Surgical Adjuvant Breast and Bowel Project Breast Cancer Prevention Trial Investigators. J Natl Cancer Inst 2001; 93: 16-21.

52. Guo S, Copps KD, Dong X, Park S, Cheng Z, Pocai A et al. The Irs1 branch of the insulin signaling cascade plays a dominant role in hepatic nutrient homeostasis. Mol Cell Biol 2009; 29: 5070-5083.

53. Zebisch K, Voigt V, Wabitsch M, Brandsch M. Protocol for effective differentiation of 3T3-L1 cells to adipocytes. Anal Biochem 2012; 425: 88-90.

54. Sadagurski M, Cheng Z, Rozzo A, Palazzolo I, Kelley GR, Dong X et al. IRS2 increases mitochondrial dysfunction and oxidative stress in a mouse model of Huntington disease. J Clin Invest 2011; 121: 4070-4081.

55. Benani A, Troy S, Carmona MC, Fioramonti X, Lorsignol A, Leloup C et al. Role for mitochondrial reactive oxygen species in brain lipid sensing: redox regulation of food intake. Diabetes 2007; 56: 152-160.

(i) Cell Death and Disease is an open-access journal published by Nature Publishing Group. This work is licensed under a Creative Commons Attribution 4.0 International Licence. The images or other third party material in this article are included in the article's Creative Commons licence, unless indicated otherwise in the credit line; if the material is not included under the Creative Commons licence, users will need to obtain permission from the licence holder to reproduce the material. To view a copy of this licence, visit http://creativecommons.org/licenses/by/4.0

Supplementary Information accompanies this paper on Cell Death and Disease website (http://www.nature.com/cddis) 